\title{
Inhibitory effect of Japanese rice-koji miso extracts on hepatitis $A$ virus replication in association with the elevation of glucose-regulated protein 78 expression
}

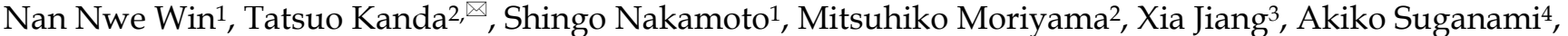 \\ Yutaka Tamura ${ }^{4}$, Hiroaki Okamoto5 ${ }^{5}$, Hiroshi Shirasawa ${ }^{\natural}$ \\ 1. Department of Molecular Virology, Graduate School of Medicine, Chiba University, 1-8-1 Inohana, Chuo-ku, Chiba 260-8670, Japan \\ 2. Division of Gastroenterology and Hepatology, Department of Medicine, Nihon University School of Medicine, 30-1 Oyaguchi-Kamicho, Itabashi-ku, Tokyo \\ 173-8610, Japan \\ 3. Department of General Surgery, The First Hospital of Hebei Medical University, Shijiazhuang, Hebei 050031, P.R. China \\ 4. Department of Bioinformatics, Graduate School of Medicine, Chiba University, 1-8-1 Inohana, Chuo-ku, Chiba 260-8670, Japan \\ 5. Division of Virology, Department of Infection and Immunity, Jichi Medical University School of Medicine, 3311-1 Yakushiji, Shimotsuke, Tochigi 329-0498, \\ Japan \\ $\triangle$ Corresponding author: Tatsuo Kanda, M.D., Ph.D., Associate Professor, Division of Gastroenterology and Hepatology, Department of Medicine, Nihon \\ University School of Medicine, 30-1 Oyaguchi-Kamicho, Itabashi-ku, Tokyo 173-8610, Japan; kanda.tatsuo@nihon-u.ac.jp; Tel.: +81-3-3972-8111 (ext.2424)
}

(C) Ivyspring International Publisher. This is an open access article distributed under the terms of the Creative Commons Attribution (CC BY-NC) license (https://creativecommons.org/licenses/by-nc/4.0/). See http://ivyspring.com/terms for full terms and conditions.

Received: 2018.05.26; Accepted: 2018.06.30; Published: 2018.07.30

\begin{abstract}
Hepatitis A virus (HAV) infection is one of the major causes of acute hepatitis and acute liver failure in developing and developed countries. Although effective vaccines for HAV infection are available, outbreaks of HAV infection still cause deaths, even in developed countries. One approach to control HAV infection is prevention through diet, which can inhibit HAV propagation and replication. Glucose-regulated protein 78 (GRP78) is a member of the heat shock protein 70 family of molecular chaperone required for endoplasmic reticulum stress and stress-induced autophagy. We previously showed that the elevation of GRP78 expression inhibits HAV replication. It has been reported that Japanese miso extracts, which was made from rice-koji, enhance GRP78 expression. In the present study, we used human hepatoma Huh7 cells and human hepatocyte PXB cells to examine the efficacy of Japanese miso extracts as antiviral agents against HAV. Japanese miso extracts enhanced GRP78 expression and inhibited HAV replication in human hepatocytes. Together, these results demonstrate that Japanese miso extracts may partly modulate GRP78 expression and additively or synergistically work as antivirals against HAV infection. Japanese miso extracts can be used as effective dietary supplements for severe hepatitis A.
\end{abstract}

Key words: HAV; miso; GRP78; rice-koji; ER stress

\section{Introduction}

Hepatitis A virus (HAV) infects humans through the fecal-oral route and causes self-limited acute hepatitis in most cases [1, 2]. The incidence of HAV infection is associated with socio-economic conditions such as sanitation, quality of water and income [1]. HAV infection causes acute hepatitis and occasionally causes acute liver failure and death in developing and developed countries [3-6]. In a recent outbreak of hepatitis A in California, U.S., over 10 people died [5, 6], even though effective vaccines for HAV have been developed $[7,8]$. Therefore, effective antivirals and host-targeting drugs against HAV should be developed.

We previously observed that HAV replication was associated with a reduction in glucose-regulated protein 78 (GRP78) expression [9] and reported that GRP78 is an antiviral against HAV infection [10]. Miso is a traditional Japanese seasoning and is used for miso soup, a Japanese culinary staple. It has also been reported that Japanese miso extract increases GRP78 expression and suppresses ultraviolet $C$ mutagenesis [11]. In the present study, we examined whether Japanese miso extracts could suppress HAV replication in human hepatocytes. 


\section{Materials and Methods}

\section{Cell lines and reagents}

The human hepatoma cell line Huh7, which was kindly gifted from Prof. R. Bartenschlager [12], was maintained in Dulbecco's modified Eagle's medium (DMEM) (Sigma-Aldrich, St. Louis, MO, USA) supplemented with $2-10 \%$ fetal bovine serum (FBS, Thermo Fisher Scientific, Yokohama, Japan), and 1\% penicillin/streptomycin (Thermo Fisher Scientific) under $5 \% \mathrm{CO}_{2}$ at $37^{\circ} \mathrm{C}$. Huh7 cells can support HAV replication and be used for the screening for antivirals against HAV $[13,14]$.

Human hepatocyte PXB cells (PhenixBio, Higashi-Hiroshima, Japan), which were derived from chimeric mice with hepatocyte-humanized liver (PXB-mouse), were grown in DMEM (Sigma) supplemented with $2 \%$ FBS, $20 \mathrm{mM}$ HEPES, $44 \mathrm{mM}$ sodium bicarbonate $\left(\mathrm{NaHCO}_{3}\right), 15 \mu \mathrm{g} / \mathrm{mL}$ L-proline, $0.25 \mu \mathrm{g} / \mathrm{mL}$ insulin, $50 \mathrm{nM}$ dexamethasone, $5 \mathrm{ng} / \mathrm{mL}$ epidermal growth factor (EGF), $0.1 \mathrm{mM}$ ascorbic acid 2-phosphate (Asc-2P) and 2\% dimethyl sulfoxide (DMSO) [2\% DMSO-supplemented hepatocyte clonal growth medium (dHCGM)] at $37{ }^{\circ} \mathrm{C}$ and $5 \% \mathrm{CO}_{2}$ as previously described [15].

Two types of Japanese rice-koji miso, Kurasaigetsuusujiomiso (KU) and Igoumiso (IG), were purchased from Ando Brewery (Kakunodate, Japan) [11]. KU is made from rice (Kitauramura, Akita, Japan), soy (Akita, Japan), and salt with special Yurara yeast (Akita Japan) [16]. IG is made from rice (Kitauramura, Akita, Japan), soy with performing husk-removing treatment (Japan), and salt [16]. Miso extracts were prepared as previously described [11], and the supernatant was then filtered through a 0.45 $\mu \mathrm{m}$ membrane (IWAKI Glass, Japan).

\section{Infection of hepatocytes with HAV}

Approximately $1.0 \times 10^{5} \mathrm{Huh} 7$ cells or $4.0 \times 10^{5}$ PXB cells were washed with PBS twice, and infected with HAV HA11-1299 genotype IIIA strain [13] at a multiplicity of infection (MOI) of 0.01 in $2 \%$ FBS media. After 6 hours, media were exchanged, and cells were incubated with or without miso extracts. Huh7 cells and PXB cells were maintained in DMEM supplemented with $2 \%$ FBS and AHCGM (PhenixBio), respectively. At days 1 and 4 post-infection, the media were exchanged, and miso extracts were added. One week after infection, total cellular RNA was extracted for further analysis.

\section{RNA extraction and quantitation of HAV RNA}

Total cellular RNA was extracted using an RNeasy Mini kit (Qiagen, Hilden, Germany) according to the manufacturer's instructions. Reverse transcription was performed at $37{ }^{\circ} \mathrm{C}$ for $15 \mathrm{~min}$, followed by $85{ }^{\circ} \mathrm{C}$ for 5 s. For HAV, GRP78 and glyceraldehyde-3-phosphate dehydrogenase (GAPDH) mRNA quantification, the following primer sets were respectively used: sense primer, 5'-AGGCTACGGGTGAAACCTCTTAG-3', and antisense primer, 5'-GCCGCTGTTACCCTATCCAA3'; sense primer, 5'-GCCTGTATTTCTAGACCTGCC$3^{\prime}$, and antisense primer, 5'-TTCATCTTGCCAGCCA GTTG-3'; and sense primer, 5'-ACCCACTCCTCCAC CTTTG-3', and antisense primer, 5'-CTCTTGTGCTCT TGCTGGG-3' [13, 9]. Real-time PCR was performed with Power SyBr Green Master Mix (Applied Biosystems, Thermo Fisher Scientific, Inc., Waltham, MA, USA) on a StepOne Real-time PCR system (Applied Biosystems). The PCR reaction was performed as follows: $95^{\circ} \mathrm{C}$ for $10 \mathrm{~min}$, followed by 40 cycles of $95{ }^{\circ} \mathrm{C}$ for $15 \mathrm{~s}$ and $60{ }^{\circ} \mathrm{C}$ for $1 \mathrm{~min}$. Data analysis was based on the ddCt method.

\section{Western blot analysis}

Cell lysates were collected using $50 \mu \mathrm{L} 1 \times$ sodium dodecyl sulfate (SDS) sample buffer. After sonication, proteins were subjected to SDSpolyacrylamide gel electrophoresis (PAGE) on 5-20\% polyacrylamide gels and transferred onto polyvinylidene difluoride membranes (ATTO, Tokyo, Japan), followed by overnight blocking with $5 \%$ skim milk in PBS supplemented with Tween 20 (Bio-Rad, Hercules, CA, USA). Membranes were probed with specific antibodies against GRP78 (Cell Signaling, Boston, MA, USA), GAPDH (Santa Cruz Biotechnology, Dallas, TX, USA) or $\beta$-tubulin (Abcam, Eugene, OR, USA). After they were washed, the membranes were incubated with secondary horse-radish peroxidase-conjugated antibodies. Signals were detected using enhanced chemiluminescence (GE Healthcare, Tokyo, Japan) and scanned using an image analyzer (LAS-4000; Fuji Film, Tokyo, Japan).

\section{MTS assay}

To evaluate cell growth and viability, dimethylthiazol carboxymethoxyphenyl sulfophenyl tetrazolium (MTS) assays were performed using CellTiter 96 Aqueous One-Solution cell proliferation assay (Promega, Madison, WI, USA). Huh7 cells were incubated with $1 \mathrm{~mL}$ of fresh DMEM supplemented with $10 \%$ FBS containing $0 \%, 0.1 \%, 0.5 \%, 1 \%, 5 \%$ and $10 \%$ miso extracts. PXB cells were incubated with 1 $\mathrm{mL}$ of fresh dHCGM containing $0 \%, 0.1 \%, 0.5 \%, 1 \%$, $5 \%$ and $10 \%$ miso extracts. After 24 hours of treatment with or without miso extracts, absorbance at $490 \mathrm{~nm}$ of each well was measured with an iMark Microplate Absorbance Reader (Bio-Rad) or an ARVO MX 1420 multilabel counter (PerkinElmer, Boston, MA, USA). 
(a)

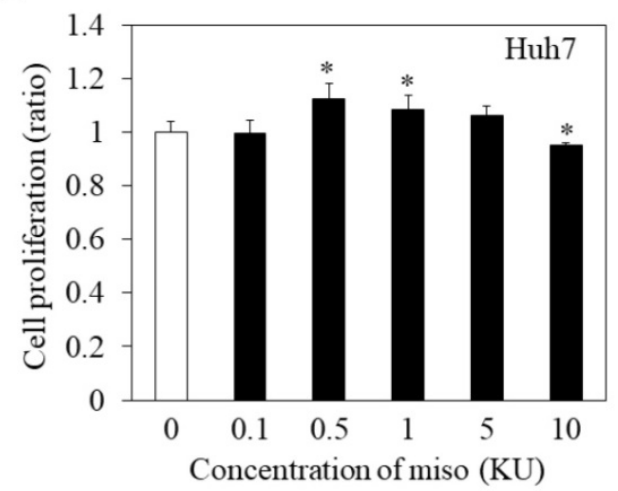

(b)

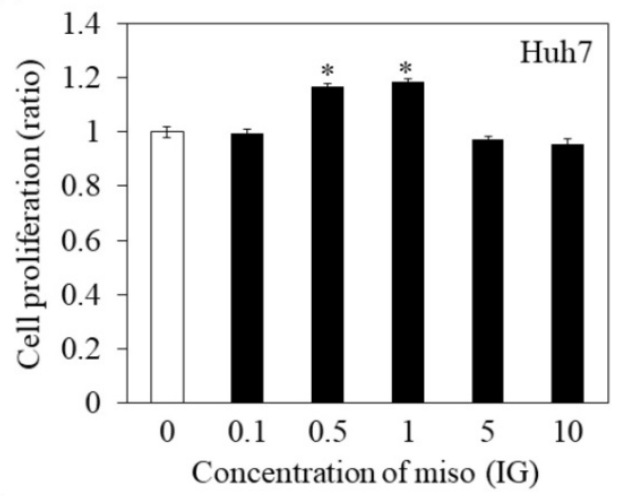

(c)

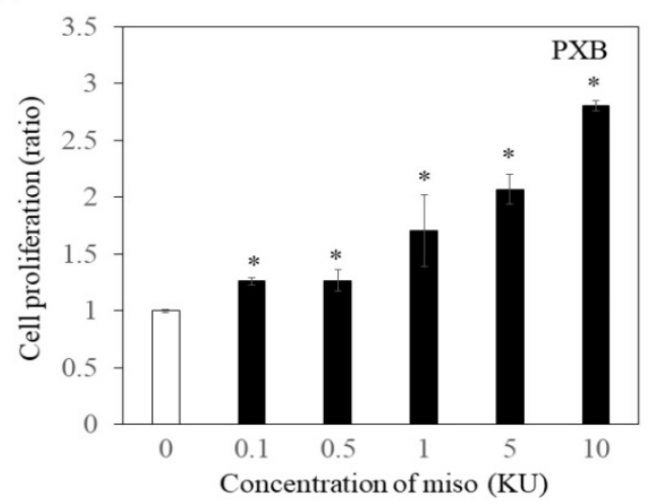

(d)

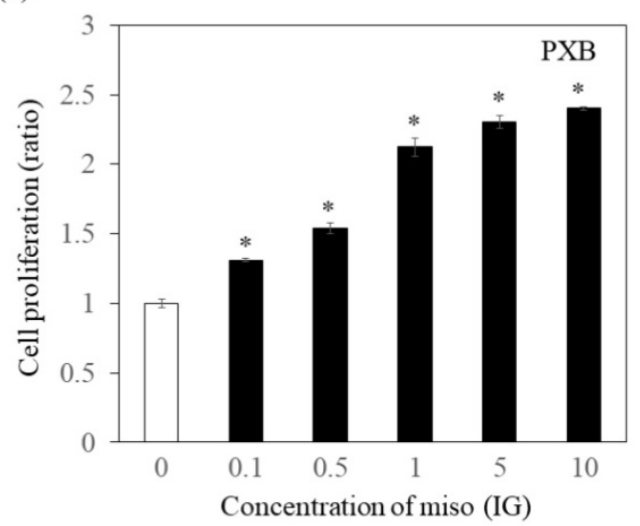

Figure 1. Effects of Japanese miso extracts on the cell viabilities of human hepatocytes. Huh7 cells were treated with Japanese miso extracts: Kurasaigetsuusujiomiso (KU) (a) and Igou-miso (IG) (b) at the indicated concentrations for 24 hours, and cell proliferation was evaluated by MTS assay. PXB cells were also incubated with KU (c) and IG (d) for 24 hours. Data are presented as the mean \pm SD of triplicate samples. ${ }^{*} \mathrm{p}<0.05$ compared to the untreated control.

\section{Statistical analysis}

Data are expressed as the mean \pm standard deviation (SD). Statistical analysis was performed using Student's t-test. The results with $\mathrm{p}<0.05$ were considered statistically significant.

\section{Results \\ Effects of miso extracts on Huh7 cells and PXB cells}

To determine the effects of Japanese miso extracts on cell proliferation (Figure 1a and 1b), Huh7 cells were incubated with KU or IG at different concentrations $(0.1 \%, 0.5 \%, 1 \%, 5 \%$ and $10 \%)$ for 24 hours, and cell viabilities were evaluated using MTS assay. The cell viabilities were reduced when Huh7 cells were incubated with $10 \% \mathrm{KU}$ or IG, compared to that of the untreated control (Figure 1a and 1b). In PXB cells, both KU and IG did not reduce cell viabilities at different concentrations $(0.1 \%, 0.5 \%, 1 \%$, $5 \%$ and $10 \%$ ) for 24 hours (Figure 1c and 1d). Therefore, we selected Japanese miso extracts at a $0.5 \%$ concentration for further analysis.

\section{Miso extracts enhance GRP78 expression and inhibit HAV replication in Huh7 cells.}

To examine the effects of miso extracts on GRP78 expression and HAV replication, Huh7 cells were incubated with KU or IG at $0.5 \%$ concentration. The expression levels of GRP78 protein were enhanced in Huh7 cells treated with miso extracts, compared with untreated control cells (Figure 2a and $2 b$ ).

We also examined whether miso extracts could inhibit HAV replication in Huh7 infected with the HAV HA11-1299 strain and incubated with or without KU and IG at a $0.5 \%$ concentration. One week after incubation, intracellular HAV RNA was measured by real-time RT-PCR. We observed that HAV RNA levels were inhibited in Huh7 cells treated with Japanese miso extracts (Figure 2c). For virus titration, although PCR may not be suitable to measure the viral titers, our previous study [17] showed the results of our real-time RT-PCR system are well correlated with those of HAV titers evaluated by ELISA [18].

In Figure 1a and 1b, proliferation of Huh7 cells was enhanced when treated with $0.5-1 \%$ of miso. The measurement of HAV RNA as absolute value indicated 0.71 -fold in $\mathrm{KU}$ at a $0.5 \%$ concentration, compared with those in control. This result demonstrated that $0.5 \%$ of miso (KU) did not enhance HAV replication in Huh7 cells although the difference of cell number may affect relative values of HAV RNA to GAPDH. 
(a)

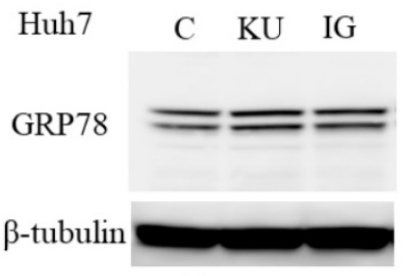

(b)

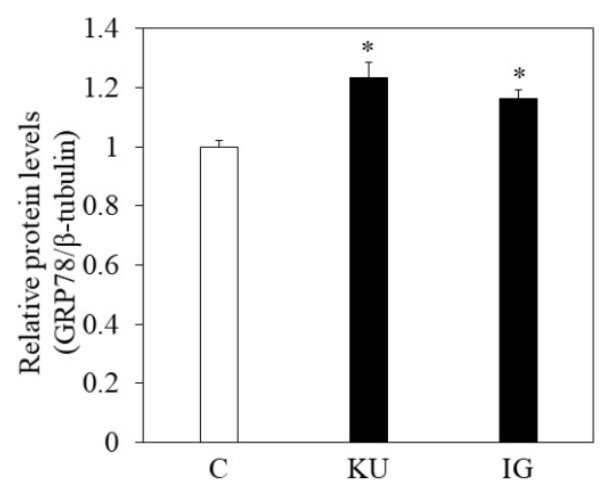

(c)

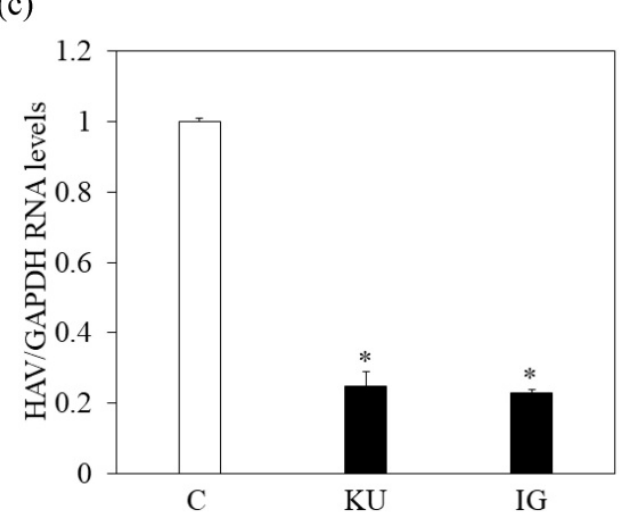

Figure 2. Japanese miso extracts enhance GRP78 expression and inhibit HAV HA11-1299 genotype IIIA strain replication in Huh7 cells. Western blot analysis of GRP78 and $\beta$-tubulin expression levels in Huh7 cells treated with or without $0.5 \%$ Kurasaigetsuusujiomiso (KU) or $0.5 \%$ Igou-miso (IG) for 24 hours (a), (b). (c) KU or IG inhibits HAV replication in Huh7 cells. HAV RNA levels were measured by real-time RT-PCR. *p $<0.05$ compared to the untreated control (C). Data are presented as the mean \pm SD of triplicate samples.

\section{Miso extract enhances GRP78 expression and inhibits HAV replication in PXB cells.}

There were no different effects on HAV replication in Huh7 cells between KU and IG. To examine the effect of KU, which has lower salts, on GRP78 expression and HAV replication in PXB cells, cells were incubated with KU at $0.5 \%$ concentration. GRP78 protein expression was greatly enhanced in PXB cells treated with KU, compared with the untreated control (Figure $3 a$ and $3 b$ ).

PXB cells can support hepatitis B virus (HBV) replication [15], but it is unclear whether these cells can support HAV replication or not. We found that PXB cells were susceptible to HAV infection although the measurement of HAV RNA as absolute values indicated 0.1-fold in PXB cells, compared with those in Huh7 cells.

We also examined whether KU could inhibit HAV replication in PXB infected with HAV and incubated with or without KU at a $0.5 \%$ concentration. One week after incubation, intracellular HAV RNA was measured by real-time RT-PCR. We found that HAV RNA levels were inhibited in PXB cells treated with Japanese miso extracts (Figure 3c). The measurement of HAV RNA as absolute values indicated 0.43 -fold in $\mathrm{KU}$ at a $0.5 \%$ concentration, compared with those in control. This result demonstrated that $0.5 \%$ of miso (KU) did not enhance HAV replication in PXB cells although the difference of cell number may affect relative values of HAV RNA to GAPDH.

\section{Discussion}

In the present study, we observed that Japanese miso extract enhanced GRP78 expression and suppressed HAV replication in human hepatocytes treated with those extracts. We also found that PXB cells are susceptible to HAV and HBV infection [15] and observed that HAV replication was inhibited in PXB and Huh7 cells after treatment with KU.

GRP78 is a member of the heat shock protein 70 family of molecular chaperone required for endoplasmic reticulum (ER) stress and stress-induced autophagy. GRP78 is also associated with cancer development including hepatocellular carcinoma (HCC) although HAV does not cause cirrhosis or HCC $[19,20]$. Antiviral effects of the Japanese miso extract against HAV may partly involve the enhancement of GRP78 expression, which inhibits HAV replication $[9,10]$. Knockdown or knockout of GRP78 could enhance HAV replication [10].

Win et al. [9] also demonstrated that the ER stress inducer thapsigargin could induce GRP78 expression and inhibit HAV replication. Thapsigargin is a non-competitive inhibitor of ER $\mathrm{Ca}^{2+}$ ATPase and induces ER stress. A previous study also showed an association between viral replication and ER stress pathways [21]. However, thapsigargin is associated with cellular apoptosis and autophagy, and causes cell death $[22,23]$. In the present study, we did not demonstrate that the direct inhibition of HAV replication was caused by enhancement of GRP78 expression. 
(a)

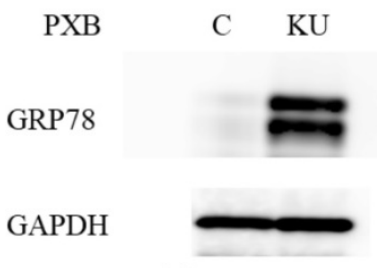

(b)

(c)
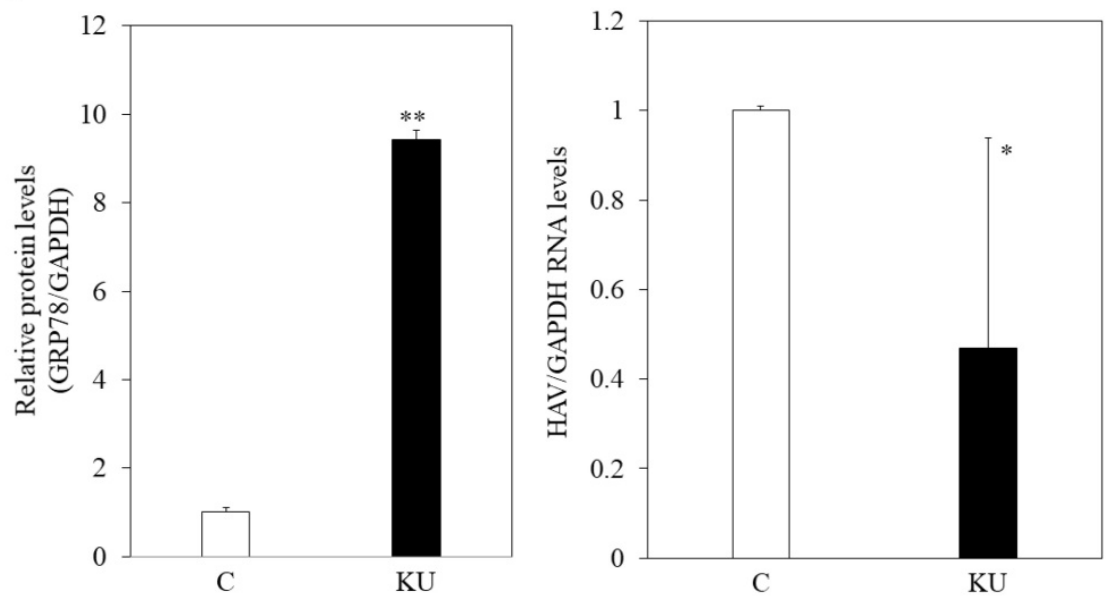

Figure 3. Japanese miso Kurasaigetsuusujiomiso (KU) extract enhances GRP78 expression and inhibits HAV HA1 1-1299 genotype IIIA strain replication in PXB cells. Western blot analysis of GRP78 and GAPDH expression levels in PXB treated with or without $0.5 \%$ KU for 24 hours (a), (b). (c) KU inhibits HAV replication in PXB. HAV RNA levels were measured by real-time RT-PCR. *p $<0.05$ and **p $<0.01$, compared to the untreated control (C). Data are presented as the mean \pm SD of triplicate samples.

Of interest, we observed the different expression levels of GRP78 and HAV RNA between two cell lines (Figures 2 and 3). It may be why Huh7 and PXB are derived from HCC and non-HCC tissues, respectively. GRP78 protects against chemical agents as well as from the natural machinery of the immune system [24]. Cancer cells resistant to destruction by $\mathrm{T}$ killer cells were found to overexpress GRP78 [24]. Human hepatoma Huh7 cells express a large amount of GRP78 at baseline, compared with primary hepatocytes PXB, which are derived from PXB mice. This seemed to cause discrepancy in the results of both cell lines. GRP78, a chaperone and master regulator of the ER stress, has been demonstrated to play a key role in several flavivirus infections [24]. Contrary to our observation, the Japanese encephalitis virus release was reduced 10-fold during siRNA knockdown of a cytoprotective agent GRP78 transcript. Virus infection can lead to significant ER stress. Further studies will be needed about the association between GRP78 and HAV replication $[9,10]$.

On the other hand, $0.5 \%$ miso extracts do not have any strong cytotoxicity (Figure 1). It may be high concentration for liver cell when considering the amount of miso consumption because the concentration of miso soup is $\sim 10 \%$ miso extracts. However, it is possible that concentration of miso ingredients in the liver after absorption might be higher than those concentration. There are three types of miso: rice-koji miso, soybean-koji miso and barley-koji miso [11]. In the present study, we used rice-koji miso. In general, Japanese people like miso and consume it every day in their meals. Khan et al. [25] found that miso soup significantly decreased the risk of gastric cancer. In addition, Sharp et al. [26] reported that the consumption of miso soup and other soya foods may reduce the risk of HCC. Moreover, Ito et al. [27] demonstrated that the effects of the habitual consumption of miso soup might decrease the heart rate.

It was reported that soybean $\beta$-conglycininderived peptides have antiviral effects [28]. A prospective randomized clinical trial also showed that soy supplementation decreased ALT levels and may improve hepatic inflammation in patients with hepatitis C virus [29]. Although both KU and IG are rice-koji miso, we also demonstrated that these rice-koji miso had antiviral effects against HAV. Therefore, it has been noted that miso has several beneficial effects on non-communicable and communicable diseases $[11,29,30]$.

In the Tokyo area, only $14 \%$ of Japanese people have anti-HAV antibodies [31], as socio-economic conditions such as sanitation have been improved. It is possible that an epidemic outbreak of HAV may 
occur in communities or even extend to several countries. As the mode of transmission of HAV is through the mouth, it may be advantageous to take miso orally to prevent HAV infection. Japanese miso extract may prevent patients with acute hepatitis A from progressing to acute liver failure. In South Korea adjacent to Japan, they also have another rice-koji miso and recently had large hepatitis A outbreaks [32]. In Japan, we have not recently experienced large hepatitis A outbreaks although there were small hepatitis A outbreaks [33]. Socio-economic factors, lifestyle preferences, dietary habits, and many more factors could be responsible for the differences in HAV outbreaks in South Korea versus Japan.

In conclusion, Japanese miso extracts exert a significant effect on the inhibition of HAV replication in human hepatocytes in association with the elevation of GRP78. Mechanism of the antiviral action of Japanese miso extracts should be explored.

\section{Abbreviations}

HAV: hepatitis A virus; GRP78: glucoseregulated protein 78 ; $\mathrm{HBV}$ : hepatitis $\mathrm{B}$ virus; $\mathrm{KU}$ : Kurasaigetsuusujiomiso; IG: Igoumiso; MOI: multiplicity of infection; GAPDH: glyceraldehyde-3phosphate dehydrogenase; HCC: hepatocellular carcinoma; ER: endoplasmic reticulum.

\section{Acknowledgments}

We thank Prof. R. Bartenschlager, Johannes-Gutenberg University Mainz, Germany for giving us Huh7 cells. This research was partly supported by the Japan Agency for Medical Research and Development (AMED) under Grant Number JP17km0908001 and JP18fk0210043.

\section{Author contributions}

Win NN, Kanda T, Nakamoto S, and Jiang $X$ contributed to study conception and design, data acquisition, data analysis and interpretation; Win NN and Kanda $\mathrm{T}$ contributed to drafting the article; all authors contributed to making critical revisions and contributed to final approval of the version of the article to be published.

\section{Competing Interests}

The authors have declared that no competing interest exists.

\section{References}

1. KusovY, Kanda T, Palmenberg A, et al. Silencing of hepatitis A virus infection by small interfering RNAs. J Virol. 2006; 80: 5599-610. DOI: 10.1128/JVI.01773-05. PMID: 16699041.

2. Yoon EL, Sinn DH, Lee HW, et al. Current status and strategies for the control of viral hepatitis A in Korea. Clin Mol Hepatol. 2017; 23: 196-204. DOI: 10.3350/cmh.2017.0034. PMID: 28942621.
3. Kanda T, Yokosuka O, Imazeki F, et al. Acute hepatitis $\mathrm{C}$ virus infection, 1986-2001: a rare cause of fulminant hepatitis in Chiba, Japan. Hepatogastroenterology. 2004; 51: 556-558. PMID: 15086201.

4. Belyhun Y, Maier M, Mulu A, et al. Hepatitis viruses in Ethiopia: a systematic review and meta-analysis. BMC Infect Dis. 2016; 16: 761. DOI: 10.1186/s12879-016-2090-1. PMID: 27993129.

5. [Internet] BBC News 2017. California hepatitis A outbreak death toll climbs to 19. Accessed on 12/13/2017. http://www.bbc.com/news/world-us-canada -41660456 .

6. [Internet] CNN 2017. San Diego County tackles hepatitis A after outbreak kills 16. Accessed on 12/13/2017. http://edition.cnn.com/2017/09/14/health/ hepatitis-a-outbreak-san-diego-county/index.html

7. Debing Y, Neyts J, Thibaut HJ. Molecular biology and inhibitors of hepatitis A virus. Med Res Rev. 2014; 34: 895-917. DOI: 10.1002/med.21292. PMID: 23722879.

8. Kanda T, Nakamoto S, Wu S, et al. Direct-acting antivirals and host-targeting agents against the hepatitis A virus. J Clin Transl Hepatol. 2015; 3: 205-10. DOI: 10.14218/JCTH.2015.00016. PMID: 26623267.

9. Win NN, Kanda T, Nakamura M, et al. Free fatty acids or high-concentration glucose enhances hepatitis A virus replication in association with a reduction in glucose-regulated protein 78 expression. Biochem Biophys Res Commun 2017; 483: 694-9. DOI: 10.1016/j.bbrc.2016.12.080. PMID: 27986562.

10. Jiang X, Kanda T, Haga Y, et al. Glucose-regulated protein 78 is an antiviral against hepatitis A virus replication. Exp Ther Med. 2017; 13: 3305-8. DOI: 10.3892/etm.2017.4407. PMID: 28587404

11. Jiang X, Ren Q, Chen SP, et al. UVC mutagenicity is suppressed in Japanese miso-treated human RSa cells, possibly via GRP78 expression. Biosci Biotechnol Biochem. 2011; 75: 1685-91. DOI: 10.1271/bbb.110175. PMID: 21897041

12. Lohmann V, Körner F, Koch J, et al. Replication of subgenomic hepatitis C virus RNAs in a hepatoma cell line. Science. 1999; 285: 110-3. DOI: 10.1126/science.285.5424.110. PMID: 10390360.

13. Jiang X, Kanda T, Nakamoto S, et al. The JAK2 inhibitor AZD1480 inhibits hepatitis A virus replication in Huh7 cells. Biochem Biophys Res Commun. 2015; 458: 908-12. DOI: 10.1016/j.bbrc 2015.02.058. PMID: 25704089.

14. Kanda T, Sasaki R, Nakamoto S, et al. The sirtuin inhibitor sirtinol inhibits hepatitis A virus (HAV) replication by inhibiting HAV internal ribosomal entry site activity. Biochem Biophys Res Commun. 2015; 466: 567-71. DOI: 10.1016/j.bbrc.2015.09.083. PMID: 26388050

15. Sasaki R, Kanda T, Wu S, et al. Association between hepatitis B virus and MHC class I polypeptide-related chain A in human hepatocytes derived from human-mouse chimeric mouse liver. Biochem Biophys Res Commun. 2015; 464: 1192-5. DOI: 10.1016/j.bbrc.2015.07.102. PMID: 26212443.

16. [Internet] Ando Brewery (in Japanese) 2018. Accessed on 3/30/2018. http:/ / www andojyozo.co.jp.

17. Jiang $\mathrm{X}, \mathrm{Kanda} \mathrm{T}, \mathrm{Wu} \mathrm{S}$, et al. Suppression of La antigen exerts potential antiviral effects against hepatitis A virus. PLoS One. 2014; 9: e101993. DOI: 10.1371/journal.pone.0101993. PMID: 24999657.

18. Yang L, Kiyohara T, Kanda T, et al. Inhibitory effects on HAV IRES-mediated translation and replication by a combination of amantadine and interferon-alpha. Virol J. 2010; 7: 212. DOI: 10.1186/1743-422X-7-212. PMID: 20815893

19. Shuda M, Kondoh N, Imazeki N, et al. Activation of the ATF6, XBP1 and grp78 genes in human hepatocellular carcinoma: a possible involvement of the ER stress pathway in hepatocarcinogenesis. J Hepatol. 2003; 38: 605-14. DOI: 10.1016/S0168-8278(03)00029-1. PMID: 12713871.

20. Jiang $X$, Kanda T, Nakamoto S, et al. Involvement of androgen receptor and glucose-regulated protein $78 \mathrm{kDa}$ in human hepatocarcinogenesis. Exp Cell Res. 2014; 323: 326-336. DOI: 10.1016/j.yexcr.2014.02.017. PMID: 24583399.

21. Huang KL, Lai YK, Lin CC, et al. Involvement of GRP78 in inhibition of HBV secretion by Boehmeria nivea extract in human HepG2 2.2.15 cells. J Viral Hepat. 2009; 16: 367-375. DOI: 10.1111/j.1365-2893.2009.01072.x. PMID: 19228285

22. Ganley IG, Wong PM, Gammoh N, et al. Distinct autophagosomal-lysosomal fusion mechanism revealed by thapsigargin-induced autophagy arrest. Mol Cell. 2011; 42: 731-43. DOI: 10.1016/j.molcel.2011.04.024. PMID: 21700220.

23. Jiang $X$, Kanda $T$, Wu S, et al. Hepatitis $C$ virus nonstructural protein $5 \mathrm{~A}$ inhibits thapsigargin-induced apoptosis. PLoS One. 2014; 9: e113499. DOI: 10.1371/journal.pone.0113499. PMID: 25409163.

24. Lewy TG, Grabowski JM, Bloom ME. BiP: Master Regulator of the Unfolded Protein Response and Crucial Factor in Flavivirus Biology. Yale J Biol Med. 2017; 90: 291-300. PMID: 28656015.

25. Khan MM, Goto R, Kobayashi K, et al. Dietary habits and cancer mortality among middle aged and older Japanese living in hokkaido, Japan by cancer site and sex. Asian Pac J Cancer Prev. 2004: 5: 58-65. PMID: 15075007.

26. Sharp GB, Lagarde F, Mizuno $T$, et al. Relationship of hepatocellular carcinoma to soya food consumption: a cohort-based, case-control study in Japan. Int J Cancer. 2005; 115: 290-5. DOI: 10.1002/ijc.20897. PMID: 15688396.

27. Ito K, Miyata K, Mohri M, et al. The effects of the habitual consumption of miso soup on the blood pressure and heart rate of Japanese adults: a cross-sectional study of a health examination. Intern Med. 2017; 56: 23-29. DOI: 10.2169/internalmedicine.56.7538. PMID: 28049996.

28. Matemu AQ, Nakamura $\mathrm{K}$, Kayahara $\mathrm{H}$, et al. Enhanced antiviral activity of soybean $\beta$-conglycinin-derived peptides by acylation with saturated fatty 
acids. J Food Sci. 2011; 76: M299-M304. DOI: 10.1111/j.1750-3841.2011.02248.x. PMID: 22417502

29. Oliveira LP, de Jesus RP, Boulhosa RS, et al. Effect of soy protein supplementation in patients with chronic hepatitis C: a randomized clinical trial. World J Gastroenterol. 2012; 18: 2203-2211. DOI: 10.3748/wjg.v18.i18.2203. PMID: 22611313.

30. Watanabe H, Sasatani M, Doi T, et al. Protective effects of Japanese soybean paste (miso) on stroke in Stroke-Prone Spontaneously Hypertensive Rats (SHRSP). Am J Hypertens. 2017; 31: 43-7. DOI: 10.1093/ajh/hpx129. PMID: 28985324.

31. Yan J, Kanda T, Wu S, et al. Hepatitis A, B, C and E virus markers in Chinese residing in Tokyo, Japan. Hepatol Res. 2012; 42: 974-81. DOI: 10.1111/j.1872-034X.2012.01009.x. PMID: 22524475.

32. Kanda T, Jeong SH, Imazeki F, et al. Analysis of 5 ' nontranslated region of hepatitis A viral RNA genotype I from South Korea: comparison with disease severities. PLoS One. 2010; 5: e15139. DOI: 10.1371/journal.pone.0015139. PMID: 21203430

33. Tominaga A, Kanda T, Akiike T, et al. Hepatitis A outbreak associated with a revolving sushi bar in Chiba, Japan: Application of molecular epidemiology. Hepatol Res. 2012; 42: 828-34. DOI: 10.1111/j.1872-034X.2012.00988.x. PMID: 22776552 